\title{
Experimental and computational study on the effects of wearing neck collar on the carotid blood flow
}

\author{
Hamidreza Ghasemi Bahraseman $^{a^{*}}$, Bahareh Hamzehei ${ }^{\mathrm{b}}$, Karim Leilnaharic, Arezoo Khosravi ${ }^{\mathrm{d}}$ \\ and Ehsan Mohseni Languria ${ }^{{ }^{*}}$
}

${ }^{a}$ Department of Mechanical Engineering, Tennessee Technological University, Cookeville, TN 38505, USA

${ }^{b}$ Department of Biomedical Engineering, Amirkabir University of Technology, Tehran, Iran

${ }^{c}$ Department of Biomedical Engineering, Science and Research Branch, Islamic Azad University, Tehran, Iran

${ }^{d}$ Atherosclerosis Research Center, Baqiyatallah University of Medical Sciences, Tehran, Iran

\begin{tabular}{l}
\hline A R T I C L E I N F O \\
\hline Article history: \\
Received September 6, 2014 \\
Accepted 22 November 2014 \\
Available online \\
23 December 2014 \\
\hline Keywords: \\
Computational fluid dynamic \\
Echo-Doppler flow \\
Football neck collar \\
Carotid artery
\end{tabular}

\section{Introduction}

Football is one of the most challenging sports in terms of critical injuries including the neck injuries. Data show that $49 \%$ to $65 \%$ of college football players suffer from stingers injuries (Clancy et al. 1977; Robertson et al. 1979; Sallis et al. 1992; Rowson et al. 2008). Several studies have been done to enhance the neck collar design and material properties to prevent rare disastrous events (Clancy 1977; Saal 1991; Sallis et al. 1992, Guyton \& Hall, 1996). Currently, many players use neck collars to reduce the adverse effects of such injuries (Rowson et al., 2008). The design of existing neck collars are mostly based on empirical information. When the player wears a neck collar, the carotid artery that

* Corresponding author. Tel: +19015678750

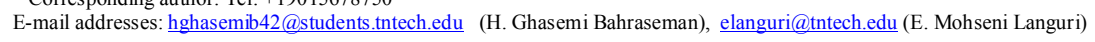

C 2015 Growing Science Ltd. All rights reserved. doi: $10.5267 /$ j.esm. 2014.12.002 
is attached to the inner part of neck collar will be under pressure. This vessel is in charge of blooding head, neck, face and some parts of brain (Guyton \& Hall, 1996) and is considered one of the most important vessels in the region. Researchers investigated the neck's range of motion limitation when different types of neck collars are used. The decreasing range of motion in the lateral flexion and extension planes due to neck injury has been investigated to quantify the effectiveness of neck collars (Hovis \& Limbird, 1994; Gorden et al, 2003). In both studies, a subject was outfitted with various neck collars experiencing quasi-static loading on the head and the motion range reduction of the neck were recorded during the test.

The current study investigates the impact of football neck collar on carotid flow. The Echo-Doppler technique is used to measure blood flow through carotid. To the authors' best of knowledge, there are no studies on the adverse influence of neck collars on carotid flow. The computational fluid dynamics (CFD) technique is employed to optimize the design of the neck collar ergonomically. This investigation was performed on ten healthy subjects using Echo-Doppler for three different categories with no neck collar (Category 1), with neck collar (Category 2), and a gap-embedded neck collar design (Category 3).

\section{Method and design of experiments}

Ten healthy male participants were subjected to right external carotid blood flow measurements for the three pre-defined categories. Informed consents were obtained from the participants were in line with accepted procedures approved by the Department of Cardiovascular Imaging (Shaheed Rajaei Cardiovascular, Medical and Research Center, Tehran, Iran). All participants were followed a physical examination via Echo-Doppler and proved to have a normal cardiovascular performance.

The participants' weights were from $67 \mathrm{~kg}$ to $95 \mathrm{~kg}$ with the average of $78.1 \mathrm{~kg}$ and their heights ranged from $168 \mathrm{~cm}$ to $188 \mathrm{~cm}$ with the average of $178 \mathrm{~cm}$. The average age of the participants was 23 years. Because of the importance of anthropometry at protective sports equipment, the neck's perimeters were evaluated before the beginning of the experiments. The mean neck circle was obtained $38.55 \mathrm{~cm}$. A commercially common ultrasonograph (Maylab, 60, BIOSOUND ESAOTE Inc., USA) was applied for sonography exams. A $4 \mathrm{MHz}$ phased-array probe was placed at the position of the right external carotid artery in order to measure the blood velocity, arterial section area and flow by the Bmode (Fig 1). Echo-Doppler images were recorded digitally and then analyzed using Maylab-Desk analyzer (Maylab, BIOSOUND ESAOTE Inc., USA). Only high-quality images were collected for processing. All tests were acquired in the sitting position and the location of right external carotid artery was recognized by carotid triangular method (Whitehead, 1997).

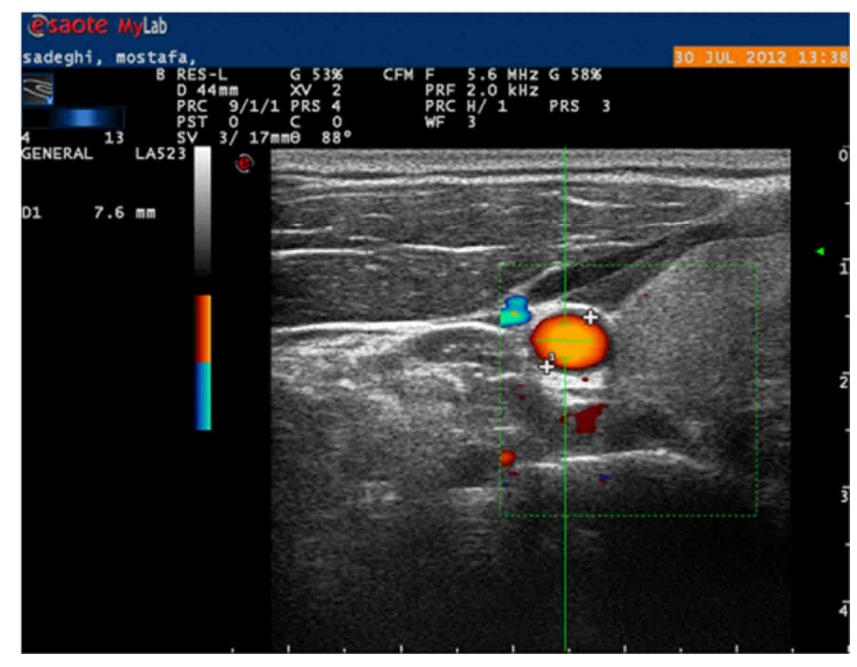

Fig. 1. Triangular sequential-monitoring of external carotid artery 


\section{Computational fluid dynamic}

The geometry of the right external carotid artery was created using the electro cardio graphic (ECG) - Doppler technique. The cross-sectional diameters recorded are $6.5 \mathrm{~mm}$ (circular cross section), $5.2 \mathrm{~mm}$ and $7.3 \mathrm{~mm}$ (oval shaped) and finally $8.6 \mathrm{~mm}$ and $4.0 \mathrm{~mm}$ (oval shape) for categories 1 to 3 , respectively. The oval cross-sectional shape of the artery was due to the excess pressure of neck collar. SolidWorks package was employed to create the computer aided design (CAD) model of the carotid artery utilizing the ECG-Doppler data (Fig. 1). For numerical modeling, the blood is assumed to be an incompressible Newtonian fluid (Caro et al., 1978) that is proved to be a valid assumption for largescale blood flows. The density and viscosity of $1056 \mathrm{~kg} / \mathrm{m}^{3}$ and $0.0035 \mathrm{~Pa} \cdot s$ were used in the model (Koch et al., 2010).

The electrical stethoscope was used to measure the applied pressure at the artery and the data were imposed to the model boundary conditions. The pressure values of 107, 123 and $114 \mathrm{mmHg}$ were recorded for categories 1 to 3, respectively and applied to the inflow and outflow boundaries of the model. The artery wall was considered rigid and the no-slip boundary conditions were applied on the walls.

The Navier-Stokes equation (Eq. 1) was solved with the fluid forces obtained from the Lagrange multipliers. This gives rise to the loading conditions declared by Eq. 1 as the Navier-Stokes equation (Espino et al, 2012). The equations are simplified regarding incompressible flow of a Newtonian fluid with constant viscosity.

$$
\rho \frac{D_{u_{i}}}{D_{t}}=-\nabla p+\rho g+\mu \nabla^{2} u
$$

In the Navier-Stokes equation, $p$ is the pressure, $\mu$ is the viscosity, $\rho$ is density and $u$ is the local velocity. Three-dimensional second order Lagrangian elements were employed for the mesh generation. Total number of 23432, 15681 and 14083 elements were used for the geometries of categories 1 to 3, respectively. The meshed geometries are shown in Fig 2.
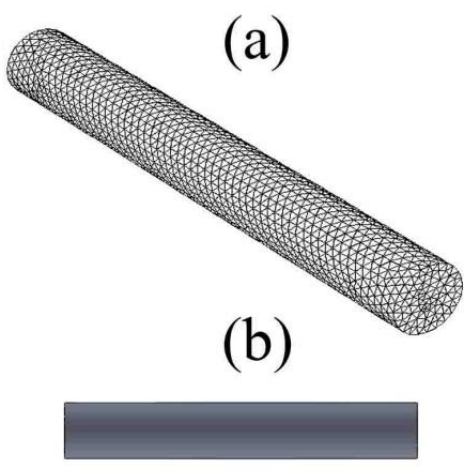

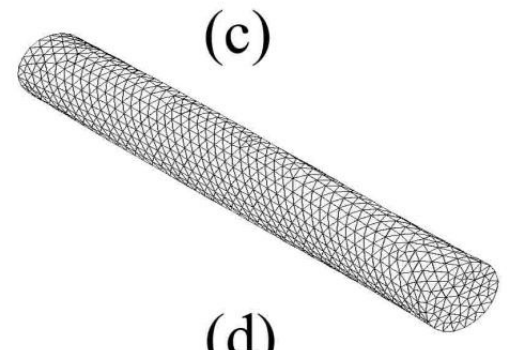

(d)

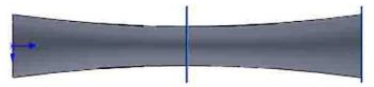

(e)

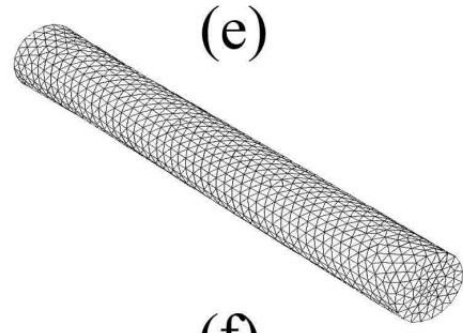

(f)

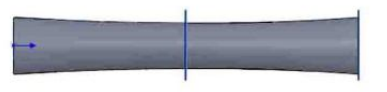

Fig. 2. Generated meshes for the geometries related to category 1 (a), category 2 (c) and category 3 (e). Lateral view of created geometries for category 1 (b), category 2 (d) and category 3 (f).

\section{Analysis}

The finite element analysis commercial package, Comsol Multi-physics (v4.2), was utilized to develop and solve the models. A direct Multi-frontal Massively Parallel Sparse (MUMPS) direct solver was used to solve the model. 


\subsection{Blood flow measurement}

The blood flow rate was computed using the stroke volume and heart rate data as follows:

$$
\text { Blood volumetruc flow }=\text { Stroke volume } \times \text { Heart rate }
$$

where the stroke volume was measured from ECG using Eq. (3):

$$
\text { Stroke volume }=\text { Velocity integration } \times \text { carotid artery section area }
$$

In the Eq. (3), the velocity integration was calculated by tracing the Doppler flow from EchoDoppler imaging technique. The carotid artery section area was measured using Eq. (4):

$$
\text { Area }=\pi\left(\frac{D}{2}\right)^{2}
$$

where $D$ is the carotid diameter. The right external carotid artery flow for all categories were calculated and demonstrated in Table 1.

\section{Table 1}

\begin{tabular}{|c|c|c|c|c|c|c|}
\hline subject & $\begin{array}{c}\text { Echo-Doppler } \\
\text { BVFECA at } \\
\text { category } 1 \\
(\mathrm{ml} / \mathrm{mi})\end{array}$ & $\begin{array}{c}\text { Echo-Doppler } \\
\text { BVFECA at } \\
\text { category } 2 \\
(\mathrm{ml} / \mathrm{min})\end{array}$ & $\begin{array}{c}\text { Echo-Doppler } \\
\text { BVFECA at } \\
\text { category } 3 \\
(\mathrm{ml} / \mathrm{min})\end{array}$ & $\begin{array}{l}\text { difference of } \\
\text { BVFECA } \\
\text { between } \\
\text { category } 1 \text { and } \\
2(\mathrm{ml} / \mathrm{min})\end{array}$ & $\begin{array}{l}\text { difference of } \\
\text { BVFECA } \\
\text { between } \\
\text { category } 1 \text { and } \\
3(\mathrm{ml} / \mathrm{min})\end{array}$ & $\begin{array}{l}\text { difference of } \\
\text { BVFECA } \\
\text { between } \\
\text { category } 2 \text { and } \\
3(\mathrm{ml} / \mathrm{min})\end{array}$ \\
\hline 1 & 1637 & 1111 & 1306 & 526 & 331 & 195 \\
\hline 2 & 1945 & 1493 & 1643 & 425 & 302 & 123 \\
\hline 3 & 1848 & 1364 & 1624 & 484 & 224 & 260 \\
\hline 4 & 1720 & 1134 & 1406 & 586 & 314 & 272 \\
\hline 5 & 1874 & 1325 & 1627 & 549 & 247 & 302 \\
\hline 6 & 1934 & 1446 & 1596 & 488 & 338 & 150 \\
\hline 7 & 1944 & 1347 & 1736 & 597 & 208 & 389 \\
\hline 8 & 1856 & 1269 & 1641 & 581 & 215 & 366 \\
\hline 9 & 1919 & 1478 & 1595 & 441 & 324 & 117 \\
\hline 10 & 1822 & 1326 & 1593 & 496 & 229 & 267 \\
\hline
\end{tabular}

The blood volumetric of external carotid artery at 3 categories and their differences. Note that BVFECA refers to the blood volumetric flow of external carotid artery.

One of the most popular and conventional brands of neck collars being used is flat football neck roll (Adams, 2014). This collar consists of a molded high-density polyurethane foam collar which are covered with vinil substance. In this study, the neck collar with the size range of 1.5 inch to 2.0 inch were used. In order to perform the testing for the Category 3 with an embedded gap, an empty space between the neck collar and the skin adjacent to the external carotid artery was created with the size equal to the largest carotid artery diameter.

\section{Results and discussion}

Comparing the results of categories 1 and 2, it is concluded that wearing the collar reduces the average blood flow of right external carotid artery (BVFECA) by $28 \%$ compared to the Category 1 without any collar (Table 1). Furthermore, the results reveal that devising the air gap in the Category 3 helped the blood flow of the right external carotid artery by only $15 \%$ deceasing its volumetric flow. To compare the neck collar with a gap (Category 3, with the average of $1576.7 \mathrm{ml} / \mathrm{min}$ ) to the neck collar without gap (Category 2, with the average of $1329.3 \mathrm{ml} / \mathrm{min}$ ), $19 \%$ increment of the BVFECA was obtained for all cases. Fig. 3 summarizes the reduction in the averaged BVFECA for the three categories. 


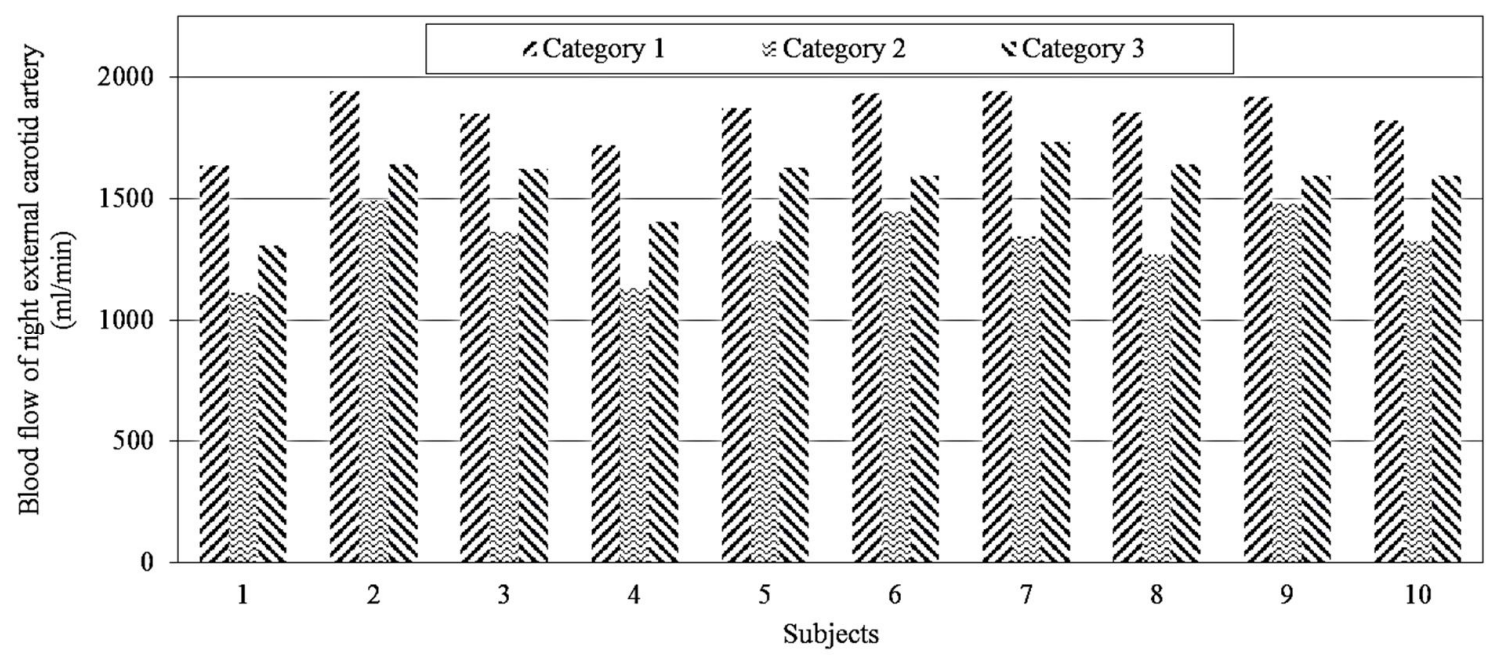

Fig. 3. The blood volumetric of right external carotid artery in the cases of without wearing neck collars (category 1), wearing neck collar without designed gap (category 2), wearing neck collar with a designed gap (category 3). As shown in Fig. 4, the blood flow reductions of carotid artery for ten subjects were measured from $10.7 \%$ to $20.2 \%$ when the neck collar was used with the embedded gap (Category 3). Furthermore, the blood flow decrement of carotid artery for mentioned subjects varied between $23.2 \%$ to $34.1 \%$ during using the neck collar without the gap (Category 1 ).

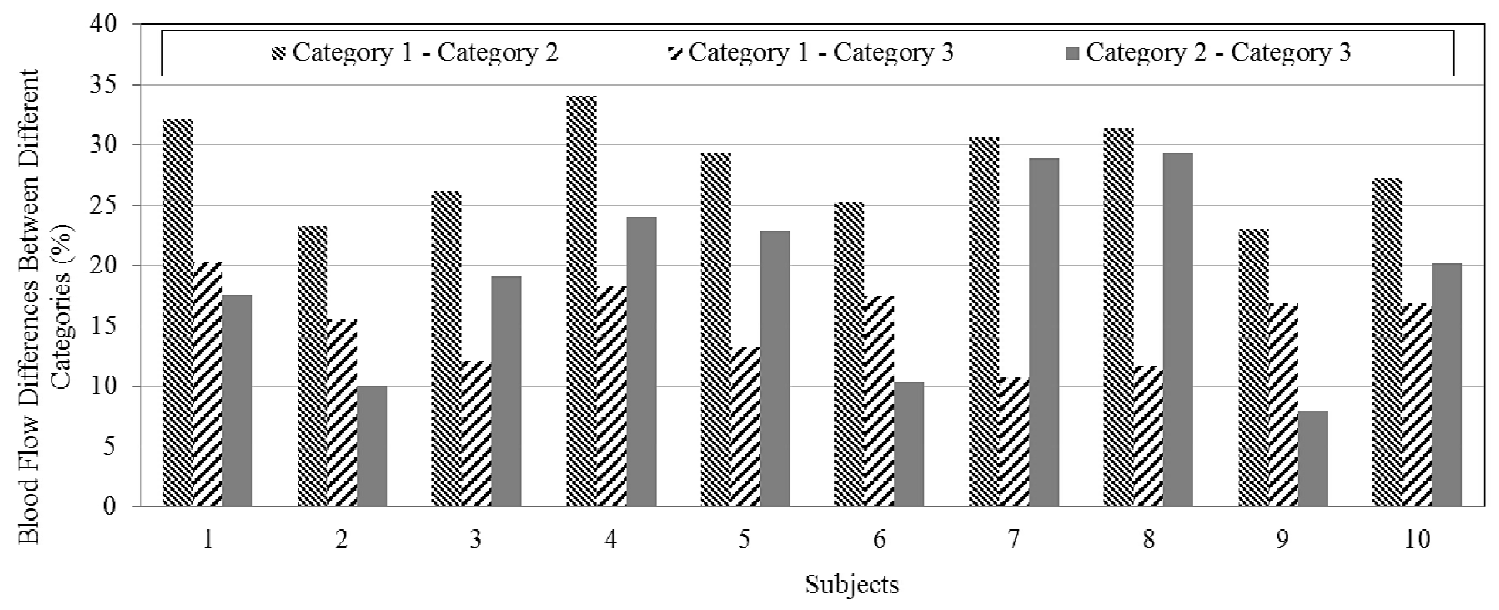

Fig. 4. Difference percentage of the blood volumetric of right external carotid artery at the categories of without wearing neck collars (category 1 ), wearing neck collar without designed gap (category 2), wearing neck collar with a designed gap (category 3 ).

As shown in Table 1, the blood flow of carotid artery under normal condition (Category 1) changed from $1637 \mathrm{ml} / \mathrm{min}$ to $1945 \mathrm{ml} / \mathrm{min}$. During using the flat football neck collar (Category 2), volumetric flow was ranged between $1111 \mathrm{ml} / \mathrm{min}$ and $1493 \mathrm{ml} / \mathrm{min}$. The results of Category 3 indicated that the blood flow of carotid artery was changed from $1306 \mathrm{ml} / \mathrm{min}$ to $1736 \mathrm{ml} / \mathrm{min}$. Table 1 also indicates that the minimum difference of flow rate between Category 1 and Category 2 was $441 \mathrm{ml} / \mathrm{min}$, the maximum difference was about $597 \mathrm{ml} / \mathrm{min}$, and the mean difference was $520 \mathrm{ml} / \mathrm{min}$. One clear fact shown in the Fig. 3 is that all participants experienced reduced blood flow in Category 2 compared to Category 1 that confidently speaks about the adverse effect of such collars on the blood flow of carotid artery. Table 1 depicts that the embedded gap in the Category 3 had the minimum and maximum differences of blood flow with respect to the Category 1 of $208 \mathrm{ml} / \mathrm{min}$ and $338 \mathrm{ml} / \mathrm{min}$, respectively. 
Results clearly show a major reduction in the blood flow of carotid artery from $1849.9 \mathrm{ml} / \mathrm{min}$ in Category 1 to $1329.3 \mathrm{ml} / \mathrm{min}$ in Category 2. This blood flow reduction was less for the Category 3 when the gap was designed into the neck collar, $1576.7 \mathrm{ml} / \mathrm{min}$. The Wilcoxon signed-rank statistical method was used to compare the results of Category 1 and Category 2. The mean ranks difference of 5.50 communicates the significant difference (P-value of 0.01 ) between the measured blood volumetric flow of carotid artery of categories 1 and 3 . Tables 2 to 4 demonstrate the averaged BVFECA and the Echo-Doppler measured values for categories of 1,2 and 3, respectively.

Table 2

Comparison of numerical and echo-Doppler measurements of the blood volumetric flow of external carotid artery at category 1 . Note that BVFECA refers to the blood volumetric flow of external carotid artery

\begin{tabular}{lccc}
\hline subject & $\begin{array}{c}\text { Echo-Doppler BVFECA at } \\
\text { category 1 (ml/mi) }\end{array}$ & $\begin{array}{c}\text { Numerical BVFECA at } \\
\text { category 1 (ml/min) }\end{array}$ & Difference $(\%)$ \\
\hline 1 & 1637 & 1456 & 11 \\
2 & 1945 & 1808 & 7 \\
3 & 1848 & 1700 & 8 \\
4 & 1720 & 1496 & 13 \\
5 & 1874 & 1611 & 14 \\
6 & 1934 & 1663 & 9 \\
7 & 1944 & 1769 & 15 \\
8 & 1856 & 1577 & 13 \\
9 & 1919 & 1669 & 15 \\
\hline
\end{tabular}

Table 3

Comparison of numerical and echo-Doppler measurements of the blood volumetric flow of external carotid artery at category 2. Note that BVFECA refers to the blood volumetric flow of external carotid artery

\begin{tabular}{|c|c|c|c|}
\hline subject & $\begin{array}{c}\text { Echo-Doppler BVFECA at } \\
\text { category } 2(\mathrm{ml} / \mathrm{mi})\end{array}$ & $\begin{array}{l}\text { Numerical BVFECA at } \\
\text { category } 2(\mathrm{ml} / \mathrm{min})\end{array}$ & Difference $(\%)$ \\
\hline 1 & 1111 & 1055 & 5 \\
\hline 2 & 1493 & 1313 & 12 \\
\hline 3 & 1364 & 1200 & 12 \\
\hline 4 & 1134 & 1043 & 8 \\
\hline 5 & 1325 & 1179 & 11 \\
\hline 6 & 1446 & 1315 & 9 \\
\hline 7 & 1347 & 1239 & 8 \\
\hline 8 & 1269 & 1091 & 14 \\
\hline 9 & 1478 & 1226 & 17 \\
\hline 10 & 1326 & 1127 & 15 \\
\hline
\end{tabular}

\section{Table 4}

Comparison of numerical and echo-Doppler measurements of the blood volumetric flow of external carotid artery at category 3 . Note that BVFECA refers to the blood volumetric flow of external carotid artery

\begin{tabular}{lccc}
\hline subject & $\begin{array}{c}\text { Echo-Doppler BVFECA at } \\
\text { category 3 }(\mathrm{ml} / \mathrm{mi})\end{array}$ & $\begin{array}{c}\text { Numerical BVFECA at } \\
\text { category 3 }(\mathrm{ml} / \mathrm{min})\end{array}$ & Difference $(\%)$ \\
\hline 1 & 1306 & 1136.22 & 13 \\
2 & 1643 & 1478.7 & 10 \\
3 & 1624 & 1364.16 & 8 \\
4 & 1406 & 1293.52 & 11 \\
5 & 1627 & 1448.03 & 12 \\
6 & 1596 & 1404.48 & 14 \\
7 & 1736 & 1492.96 & 14 \\
9 & 1641 & 1411.26 & 15 \\
\hline
\end{tabular}


Fig. 5 shows the increase of the shear rate magnitude by time. At the beginning of the systolic period, a transient and large vibration is observed in the matter of shear rate peak. The maximum of shear rate occurs at the maximum of the left ventricular systolic pressure followed by a waveform increment at the end of the systolic phase. This increment could be due to shrinking orifice region and subsequently increasing velocity magnitude across this region. The peak of blood flow during the systolic phase has a transient and sudden augment as shown in Fig. 6. As the left ventricular systolic pressure reduces, the peak of the blood flow is decreasing as well.

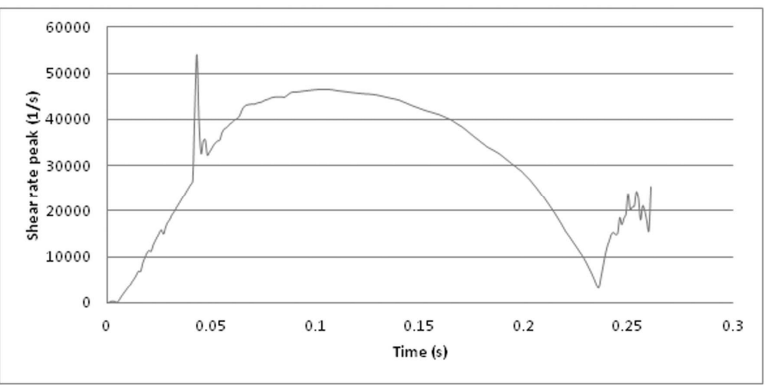

Fig. 5. Shear rate peak waveform

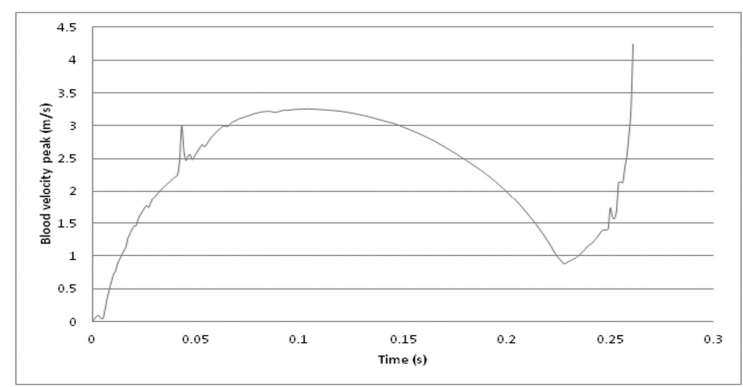

Fig. 6. Waveform of peak of blood velocity

This study was employed the Echo-Doppler measurement technique to calculate the effect of football neck collar on the blood flow rate of carotid artery of healthy subjects at different conditions. The Echo-Doppler-derived data have been compared at three categories of without wearing neck collars (Category 1), with wearing neck collar (Category 2), and wearing the neck collar with an embedded gap adjacent to external carotid artery position (Category 3 ). To the best of authors' knowledge, this is the first time that Echo-Doppler measurements have been employed for empirical estimations of neck collar performance. Results of this study showed that the blood flow rate of carotid artery was 19\% larger in Category 3 compared to Category 2 mainly due to the embedded gap. Numerical calculations were able to predict the results with $11 \%$ error compared to the clinical measurements that is considered reasonable. The data of current investigation shows the feasibility of numerical calculation of hemodynamic through the carotid artery at the three different categories. The results suggest that a three-dimensional model would predict hemodynamic performance within relatively short solution time (less than 10 minutes) with significantly less cost compared to clinical measurements. Since the carotid artery is in charge of blooding the face, brain and eyes, the carotid flow reduction due to using the neck collar could results in some disorders for players in long term including headache, weakness and feeling of dizziness. Such disorders can affect the concentration and the performances of players, adversely. However, this study has some specific limitations which is listed below:

(1) The current study has been done for static subjects rather than dynamic players. Although football players are moving, the validated numerical approach in this paper could be used for the dynamic case. However, all commercially available football neck collars are lack of the designed gap in this study. But the gap size should be investigated regarding the age and neck circle of footballers in order for finding an ideal diameter. Although, flow measurement during activities would be challenging.

(2) The commercially available ultrasonograph (Maylab, 60, BIOSOUND ESAOTE Inc., USA) used in this clinical study has a reported precision of \pm 11 for the blood volumetric flow (Maylab advanced operation's user manual, 2008).

(3) The current study is performed for a conventional neck collar. Future trends can be focused on the other kinds of neck collars. 


\section{Conclusion}

A series of tests were performed on three different categories of participants without neck collar, with neck collar and finally with a gap-embedded neck collar to evaluate the effect of neck collar on carotid flow for ten subjects. Results showed a significant blood flow reduction of external carotid artery when neck collar is being used. The experimental and numerical results approved the fact that the embedded gap between the neck collar and the position adjacent to carotid artery improves the blood flow by $14 \%$. The numerical results were in a reasonably good agreement with the experimental measurements. The results suggest a gap-embedded design for the neck collar near the carotid position can improve the efficiency and convenience of players significantly with minimal disorders.

\section{References}

Adams USA, (2014): http://football.epicsports.com/prod/9350/adams-232-flat-contour-football-neckroll-pads.html

Bahraseman, H. G., Hassani, K., Khosravi, A., Navidbakhsh, M., Espino, D. M., Fatouraee, N., \& Kazemi-Saleh, D. (2014). Combining numerical and clinical methods to assess aortic valve hemodynamics during exercise. Perfusion, 0267659114521103.

Bahraseman, H. G., Hassani, K., Navidbakhsh, M., Espino, D. M., Sani, Z. A., \& Fatouraee, N. (2013). Effect of exercise on blood flow through the aortic valve: a combined clinical and numerical study. Computer methods in biomechanics and biomedical engineering, (ahead-of-print), 1-14.

Clancy, W. G., Brand, R. L., \& Bergfield, J. A. (1977). Upper trunk brachial plexus injuries in contact sports. The American journal of sports medicine, 5(5), 209-216.

Espino, D. M., Shepherd, D. E. T., \& Hukins, D. W. L. (2012). Transient large strain contact modelling: a comparison of contact technique for simultaneous fluid-structure interaction. Comput Fluids.

Gorden, J. A., Straub, S. J., Swanik, C. B., \& Swanik, K. A. (2003). Effects of football collars on cervical hyperextension and lateral flexion. Journal of athletic training, 38(3), 209.

Guyton, A. C., Hall, J. E. (1996). Textbook of Medical Physiology. Philadelphia, PA: WB Saunders.

Hovis, W. D., \& Limbird, T. J. (1994). An evaluation of cervical orthoses in limiting hyperextension and lateral flexion in football. Medicine and science in sports and exercise, 26(7), 872-876.

Koch, T. M., Reddy, B. D., Zilla, P., \& Franz, T. (2010). Aortic valve leaflet mechanical properties facilitate diastolic valve function. Computer methods in biomechanics and biomedical engineering, 13(2), 225-234.

Maylab Users Manual. (2008). Maylab advanced operation. Newyork: BIOSOUND ESAOTE Inc.

Robertson, W. C., Eichman, P. L., \& Clancy, W. G. (1979). Upper trunk brachial plexopathy in football players. JAMA, 241(14), 1480-1482.

Rowson, S., McNeely, D. E., Brolinson, P. G., \& Duma, S. M. (2008). Biomechanical analysis of football neck collars. Clinical Journal of Sport Medicine, 18(4), 316-321.

Saal, J. A. (1991). Common American football injuries. Sports medicine, 12(2), 132-147.

Sallis, R. E., Jones, K., \& Knopp, W. (1992). Burners: offensive strategy for an underreported injury. Physician and sportsmedicine, 20(11), 47-55.

Whitehead, J. (1997). The design and analysis of sequential clinical trials. John Wiley \& Sons. 